\title{
A CONTRADIÇÃO GESTÃO DEMOCRÁTICA X ADMINISTRAÇÃO BUROCRÁTICA DA ESCOLA: APONTAMENTOS PARA O DEBATE
}

\author{
LA CONTRADICIÓN GESTIÓN DEMOCRÁTICA X ADMINISTRACIÓN \\ BUROCRÁTICA DE LA ESCUELA: APUNTES PARA EL DEBATE
}

\author{
THE CONTRADICTION DEMOCRATIC MANAGEMENT X BUREAUCRATIC \\ ADMINISTRATION OF SCHOOL: TESTS FOR DEBATE
}

\author{
Alisson Slider do Nascimento DE PAULA ${ }^{1}$ \\ Frederico Jorge Ferreira COSTA ${ }^{2}$ \\ Kátia Regina Rodrigues LIMA $^{3}$
}

RESUMO: O referido trabalho busca empreender uma análise acerca da problemática da gestão educacional buscando desvelar o atual cenário do debate sobre a contradição entre gestão democrática e administração burocrática da escola. Para o trato metodológico utilizou-se análise de conteúdo. Em acréscimo, será a partir da pesquisa bibliográfica que foi constituído um estado da arte que buscar-se-á situar em que patamar o debate acadêmico estar tratando a temática pesquisada. Constatou-se, que o tema gestão educacional e seus apontamentos não se opõem à noção de democracia da forma de administrar uma escola, visto que o conceito de administração utilizado no conteúdo dos artigos analisados, consideram que administração configura-se como a utilização racional dos recursos para realizar seus fins, no tocante esses fins configuram-se como o processo pedagógico, isto é, o ensino e a aprendizagem.

PALAVRAS-CHAVE: Gestão democrática. Administração burocrática. Escola. Estado da arte.

RESUMEN: Este trabajo busca emprender un análisis acerca de la problemática de la gestión educativa buscando desvelar el actual escenario del debate sobre la contradicción entre gestión democrática y administración burocrática de la escuela. Para el trato metodológico se utilizó análisis de contenido. En adición, será a partir de la investigación bibliográfica que se constituyó un estado del arte que se buscará situar en que patar el debate académico esté tratando la temática investigada. Se constató que el tema gestión educativa y sus apuntes no se oponen a la noción de democracia de la forma de administrar una escuela, ya que el concepto de administración utilizado en el contenido de los artículos analizados, consideran que la administración se configura como la utilización racional de los derechos los recursos para realizar sus fines, en cuanto a esos fines se configuran como el proceso pedagógico, es decir, la enseñanza y el aprendizaje.

${ }^{1}$ Centro Universitário Inta - (UNINTA), Sobral - CE - Brasil. Professor do Centro de Carreiras da Saúde. ORCID: <http://orcid.org/0000-0001-6356-3773>.E-mail: alisson.slider@yahoo.com

${ }^{2}$ Universidade Estadual do Ceará - (UECE), Fortaleza - CE - Brasil. Professor do Programa de Pós-Graduação em Educação. ORCID: <http://orcid.org/0000-0002-8357-4557>. E-mail: frederico.costaa@uece.br

${ }^{3}$ Universidade Regional do Cariri - (URCA), Crato - CE - Brasil. Professor do Departamento de Ciências Biológicas. ORCID: <http://orcid.org/0000-0002-9132-9551>. E-mail: kareli2003@ yahoo.com.br

RPGE- Revista on line de Política e Gestão Educacional, Araraquara, v. 23, n. 2, p. 388-400, maio/ago., 2019. E-ISSN:1519-9029. 
PALABRAS CLAVE: Gestión democrática. Administración burocrática. Escuela. Estado del arte.

ABSTRACT: This work seeks to undertake an analysis about the problem of educational management, seeking to unveil the current scenario of the debate about the contradiction between democratic management and bureaucratic administration of the school. For the methodological treatment, content analysis was used. In addition, it will be from the bibliographic research that was constituted a state of the art that will seek to situate in which level the academic debate is dealing with the researched topic. It was observed that the theme of educational management and its notes do not oppose the notion of democracy in the way of administering a school, since the concept of administration used in the content of the analyzed articles considers that administration is configured as the rational use of resources to accomplish their ends, insofar as these ends are configured as the pedagogical process, that is, teaching and learning.

KEYWORDS: Democratic management. Bureaucratic administration. School. State of art.

\section{Introdução}

Os debates no âmbito educacional no Brasil correspondem, nos últimos anos, a uma grade disputa ideológica através de políticas educacionais que se inserem no sistema de ensino buscando atender os objetivos governamentais que, eventualmente, buscam configurar a educação aos patamares internacionais via avaliação em larga escala. Todavia, não obstante esse aspecto predominante, os setores dos educadores buscam, também, implementar suas concepções acerca do ensino. A gestão se situa nesse contexto, por um lado a concepção concentrada na lógica da administração burocrática da escola em que a lógica administrativa das empresas penetra no âmbito escolar em que eficiência e metas tornam-se prioridades e que o diretor incorpora o papel de gerente; por outro lado, a noção de gestão democrática em que as decisões são organizadas e deliberadas coletivamente, em que há uma participação efetiva dos sujeitos que constituem a comunidades escolar.

O presente artigo busca empreender um estado da arte acerca da problemática da gestão educacional, fazendo uso bibliografia de domínio público para identificar as perspectivas proeminentes no âmbito desta problemática. Porquanto a gestão educacional configura-se como elemento essencial e constituinte do cenário educacional nacional tanto na educação básica como na superior. Todavia, no referido trabalho dar-se-á ênfase na lógica da gestão na educação básica. 


\section{Metodologia}

O trato metodológico utilizado no presente artigo fez uso de uma análise de conteúdo. Essa técnica tem como alvo a interpretação de conteúdos de todas as classificações de documentos e textos, como estudos bibliográficos, filmes, revistas, jornais, livros, entre outros. A análise de conteúdo é indispensável para tornar exequível a interpretação textual, que requer uma investigação que tem como ponto de partida a busca pela resposta do problema delimitado na pesquisa.

A análise de conteúdo aqui proposta abordou os referenciais teóricos que tematizam a gestão educacional. A pesquisa fez uso de uma abordagem qualitativa, por corresponder à episteme do problema.

Utilizou-se como procedimento metodológico o estudo bibliográfico. De início partiuse para o levantamento de uma pesquisa, a qual tem como objetivo reunir os conhecimentos e dados sobre o problema delimitado, auxiliando para a construção da proposta. Com a escolha específica de um tema, a pesquisa bibliográfica mostrou um norte para as perguntas formuladas. A investigação bibliográfica é realizada através de materiais publicados, como livros, artigos, documentos, periódicos, sites confiáveis, entre outros.

No estudo foi fundamental selecionar critérios, como inclusão e exclusão. Com isso, os critérios de inclusão tratar-se-ão da localização dos descritores no título do texto. No que diz respeito aos critérios de exclusão, por seu turno, foi utilizada a não localização do descritor no título do texto.

Para a análise de dados foram utilizados os procedimentos: analisar, identificar, ler, reler, organizar, separar, unir, relacionar as respostas que foram encontradas nas coletas de dados. Após a execução desse procedimento, foi feita uma mediação teórica, bem como um estado da arte a partir do levantamento bibliográfico que tematize os textos acerca da gestão educacional no Brasil.

\section{Resultados e discussões}

Nesta seção foram apontados os caminhos percorridos para a construção do estado da arte da presente pesquisa. Compreende-se que esse recurso metodológico auxiliará na 
apreensão de materiais bibliográficos ${ }^{4}$, bem como na definição de categorias de análise, descritores e critérios pontuais na organização do aporte teórico-metodológico de tradição marxista que se pretende empreender. É lícito ressaltar que a problemática que se coloca na presente pesquisa se trata de buscar compreender o estado atual do debate acadêmico acerca da dicotomia entre gestão democrática e administração pública da escola.

Vale ressaltar a necessidade de pôr no corpo do texto mediações colocadas pela noção teórico-metodológica do materialismo histórico-dialético. Este método de pesquisa busca empreender uma noção de totalidade. A universalidade, particularidade e singularidade são instâncias, numa processualidade lógica, subordinadas que não entram em contradições, contudo, são distintas em uma formação de proposição.

Consoante Gamboa (1998, p. 107-108),

As pesquisas crítico-dialéticas [...] questionam fundamentalmente a visão estática da realidade implícita nas abordagens fenomenológicas e estruturalistas. Esta visão esconde o caráter conflitivo, dinâmico e histórico da realidade. Sua postura marcadamente crítica expressa a pretensão de desvendar, mais que o "conflito das interpretações", o conflito dos interesses. Essas pesquisas manifestam um "interesse transformador" das situações ou fenômenos estudados, resguardando sua dimensão sempre histórica e desvendando suas possibilidades de mudanças.

Com isso, este método busca apreender a realidade em sua totalidade, que se constitui a partir da síntese de múltiplas determinações, partindo da realidade concreta de um determinado objeto para que o mesmo identificado pelo pesquisador seja levado à abstração, a qual permitirá uma análise do fenômeno em sua totalidade, no sentido da construção de conceitos sobre o mesmo, na busca da sua essência, trazendo de novo para a concreticidade através de determinações simples (NETTO, 2011).

\section{Os procedimentos utilizados no desenvolvimento do Estado da Arte}

No desenvolvimento do procedimento de coleta de artigos em periódicos, utilizou-se apenas o repositório: Portal Periódicos Capes. Como critérios de inclusão e exclusão delimitou-se que os textos que seriam utilizados deveriam conter em seu título pelo menos um descritor que consta-se no título do trabalho; ademais, para maior refinamento da coleta,

\footnotetext{
${ }^{4}$ Os materiais bibliográficos que está sendo dado ênfase trata-se de artigos em periódicos, bem como dissertações de mestrado e teses de doutorado, além de livros especializados na área temática a qual a problemática desta pesquisa aborda.
} 
estabeleceu-se o recorte temporal de nove anos entre as publicações, compreendendo, deste modo, 2010 a 2018; ainda, os artigos selecionados tiveram que passar por avaliação por pares. Esses critérios foram estabelecidos para o refinamento mais preciso da coleta de artigos em periódicos.

A tabela 1 expõe os achados (artigos) no Portal Periódicos Capes. A categoria temática, nesse contexto, que foi selecionada tratou-se da gestão democrática por tematizar de modo mais específico e direto um dos polos da contradição destacados em na presente pesquisa. Por conseguinte, o operador booleano utilizado foi o "and", ainda, os descritores selecionados para essa categoria temática foram: educação, escola e pedagógico. Todos os descritores foram combinados com a categoria temática.

Tabela 1 - Categoria temática: Gestão democrática (Portal Periódicos CAPES)

\begin{tabular}{c|c|c|c|c}
\hline DESCRITORES/COMBINADOS & A/S.A & A/C.A & A/RESUMO & A/LE \\
\hline Gestão democrática and Educação & 52 & 30 & 12 & 9 \\
\hline Gestão democrática and Escola & 10 & 6 & 4 & 3 \\
\hline $\begin{array}{c}\text { Gestão democrática } \text { and } \\
\text { Pedagógico }\end{array}$ & 4 & 2 & 1 & 0 \\
\hline TOTAL & $\mathbf{6 6}$ & $\mathbf{3 8}$ & $\mathbf{1 6}$ & $\mathbf{1 2}$ \\
\hline
\end{tabular}

Fonte: elaboração própria

A representação dos aspectos que sistematizam a tabela explicitam-se da seguinte forma: A/S.A (Artigo Sem Aspas); A/C.A (Artigos Com Aspas); A/Resumo (Análise do Resumo); A/LE (Artigos validados para Leitura). Nessa acepção, no entrecruzamento entre Gestão democrática and educação coletou-se 52 artigos, contudo, com primeiro filtro (A/C.A), resultou em 30 artigos, com o refinamento do resumo esse número reduziu para 9 artigos selecionados para leitura, isto é, $17,3 \%$ dos achados foram validados. No entrecruzamento entre os descritores Gestão democrática and Escola coletou-se 10 artigos, contudo, após todo o processo de refinamento obteve 3 artigos, ou seja, 30\%. A combinação entre Gestão democrática and Pedagógico resultou em 4 achados, após refinamento foram validados 0 , percentual (0\%). Nesse sentido, dos 66 achados dessa categoria temática, apenas 12 foram validados $(18,2 \%)$.

Na tabela 2, tratou-se de sistematizar os achados da categoria temática: Administração burocrática. É lícito ressaltar que os mesmos descritores foram utilizados para o entrecruzamento com a categoria temática. 
Tabela 2 - Categoria temática: Administração burocrática (Portal Periódicos CAPES)

\begin{tabular}{c|c|c|l|l}
\hline DESCRITORES/COMBINADOS & A/S.A & A/C.A & A/RESUMO & A/LE \\
\hline $\begin{array}{c}\text { Administração burocrática } \text { and } \\
\text { Educação }\end{array}$ & 0 & 0 & 0 & 0 \\
\hline $\begin{array}{c}\text { Administração burocrática } \text { and } \\
\text { Escola }\end{array}$ & 2 & 1 & 1 & 1 \\
\hline $\begin{array}{c}\text { Administração burocrática } \text { and } \\
\text { Pedagógico }\end{array}$ & 0 & 0 & 0 & 0 \\
\hline TOTAL & $\mathbf{2}$ & $\mathbf{0}$ & $\mathbf{1}$ & $\mathbf{1}$ \\
\hline
\end{tabular}

Fonte: elaboração própria

A tabela 2 expressa o entrecruzamento inicial dos descritores entre Administração burocrática and Educação, não foi obtido nenhum resultado. Na combinação Administração pública and Escola 2 artigos foram coletados, contudo, após o processo de refinamento apenas 1 artigo foi validado. Na combinação dos descritores Administração burocrática and Pedagógico nenhum artigo surgiu da pesquisa. Sendo assim, o total geral de artigos achados nessa categoria temática foi de apenas 2 artigos, todavia, somente 1 artigo foi validado (50\%).

No quadro 1 são expostos os artigos selecionados, deixando explícito: ano, autor, título do artigo e título do periódico:

Quadro 1 - Periódicos selecionados Portal Periódicos Capes

\begin{tabular}{|c|c|c|c|}
\hline & & \multicolumn{2}{|c|}{ (Continua) } \\
\hline Periódico & Título & Autores (as) & Ano \\
\hline $\begin{array}{l}\text { Rev. Gest. Aval. } \\
\text { Educ. }\end{array}$ & $\begin{array}{l}\text { Gestão escolar democrática: } \\
\text { desafios e perspectivas }\end{array}$ & $\begin{array}{l}\text { Vania Regina Boschetti; } \\
\text { Assislene Barros da } \\
\text { Mota; Dayse Lúcide de } \\
\text { Freitas Abreu }\end{array}$ & 2016 \\
\hline $\begin{array}{l}\text { Educação \& } \\
\text { Sociedade }\end{array}$ & $\begin{array}{l}\text { A gestão democrática das } \\
\text { escolas: do autogoverno à } \\
\text { ascensão de uma pós- } \\
\text { democracia gestionária? }\end{array}$ & Licínio C. Lima & 2014 \\
\hline $\begin{array}{l}\text { Rev. Iberoameric. } \\
\text { Educ. }\end{array}$ & $\begin{array}{c}\text { Gestão democrática da escola no } \\
\text { Brasil: desafios à implantação } \\
\text { de um novo modelo }\end{array}$ & $\begin{array}{l}\text { Sofia Lerche Vieira; } \\
\text { Eloisa Maia Vidal }\end{array}$ & 2015 \\
\hline $\begin{array}{l}\text { Rev. Bras. Pol. } \\
\text { Admin. Educ. }\end{array}$ & $\begin{array}{c}\text { Dilemas da gestão democrática } \\
\text { da educação frente ao contexto } \\
\text { da nova gestão pública }\end{array}$ & $\begin{array}{l}\text { Luzenir Poli Coutinho; } \\
\text { Rosilene Lagares. }\end{array}$ & 2017 \\
\hline Em Aberto & $\begin{array}{l}\text { Gestão democrática da educação } \\
\text { para uma formação humana: } \\
\text { conceitos e possibilidades }\end{array}$ & $\begin{array}{c}\text { Naura Syria Carapeto } \\
\text { Ferreira }\end{array}$ & 2010 \\
\hline $\begin{array}{l}\text { Rev. Cad. Est. } \\
\text { Pesq. Educ. } \\
\text { Básica }\end{array}$ & $\begin{array}{c}\text { Concepções e práticas de gestão } \\
\text { escolar democrática na } \\
\text { educação básica no Brasil }\end{array}$ & $\begin{array}{c}\text { Walkiria de Fátima } \\
\text { Tavares de Almeida; } \\
\text { Julieta Beserra da Silva }\end{array}$ & 2017 \\
\hline $\begin{array}{l}\text { Rev. Onli. Pol. } \\
\text { Gest; Educ. }\end{array}$ & $\begin{array}{c}\text { Educação escolar e gestão } \\
\text { democrática do ensino: } \\
\text { perspectivas }\end{array}$ & $\begin{array}{c}\text { Máximo Augusto } \\
\text { Campos Masson; Maria } \\
\text { Teresa Vianna Van } \\
\text { Acker }\end{array}$ & 2018 \\
\hline
\end{tabular}




\begin{tabular}{|c|c|c|c|}
\hline $\begin{array}{l}\text { Rev. Onli. Pol. } \\
\text { Gest. Educ. }\end{array}$ & $\begin{array}{c}\text { A gestão democrática e a } \\
\text { materialização da Meta } 6 \text { do } \\
\text { Plano Nacional de Educação: } \\
\text { possibilidade de educação em } \\
\text { tempo integral na região } \\
\text { metropolitana do Estado do Rio } \\
\text { de Janeiro }\end{array}$ & Patrícia Flávia Mota & 2018 \\
\hline $\begin{array}{l}\text { Rev. Onli. Pol. } \\
\text { Gest. Educ. }\end{array}$ & $\begin{array}{l}\text { Mérito, desempenho e } \\
\text { participação nos planos } \\
\text { municipais de educação: } \\
\text { sentidos da gestão democrática }\end{array}$ & Daniela Patti do Amaral & 2016 \\
\hline $\begin{array}{l}\text { Rev. Onli. Pol. } \\
\text { Gest. Educ. }\end{array}$ & $\begin{array}{l}\text { Gestão escolar e democratização } \\
\text { da escola: desafios e } \\
\text { possibilidade de uma construção } \\
\text { coletiva }\end{array}$ & $\begin{array}{c}\text { Elisangela da Silva } \\
\text { Bernado, Amanda } \\
\text { Moreira Borde, Leonardo } \\
\text { Meirelles Cerqueira }\end{array}$ & 2018 \\
\hline $\begin{array}{l}\text { Rev. Onli. Pol. } \\
\text { Gest. Educ. }\end{array}$ & $\begin{array}{l}\text { Regulamentação da gestão } \\
\text { democrática e a ação do } \\
\text { Ministério Público: } \\
\text { desdobramentos no estado do } \\
\text { Rio de Janeiro } \\
\end{array}$ & Daniela Patti do Amaral & 2018 \\
\hline $\begin{array}{l}\text { Rev. Onli. Pol. } \\
\text { Gest. Educ. }\end{array}$ & $\begin{array}{c}\text { Gestão democrática na educação } \\
\text { infantil }\end{array}$ & $\begin{array}{l}\text { Leandra Fernandes do } \\
\text { Nascimento; Maria } \\
\text { Marina Dias Cavalcanti }\end{array}$ & 2017 \\
\hline $\begin{array}{l}\text { Pós-grad, Cent. } \\
\text { Paul. Souz.. }\end{array}$ & $\begin{array}{l}\text { Escolas de governo e seus } \\
\text { objetivos institucionais em } \\
\text { educação corporativa na } \\
\text { administração pública }\end{array}$ & $\begin{array}{l}\text { Dioni Patrícia Alves dos } \\
\text { Santos; Roberto Kanaane }\end{array}$ & 2017 \\
\hline
\end{tabular}

Fonte: elaboração própria administração pública

\section{Análise dos resultados}

A partir da coleta dos treze achados no Portal Periódicos Capes, é essencial diagnosticar os temas que se sobressaíram em suas respectivas problematizações. Com efeito, para se diagnosticar o estado em que o debate acadêmico acerca da contradição sobre gestão democrática ou administração burocrática da escola está situado, é essencial que se discuta o conteúdo de cada um dos achados.

Nessa acepção, na categoria temática "gestão democrática", em sua vinculação com o descritor educação, nove artigos foram validados. O primeiro corresponde ao artigo de Coutinho e Lagares (2017, p. 836) intitulado Dilemas da gestão democrática da educação frente ao contexto da nova gestão pública buscou empreender uma discussão que localize a "gestão democrática no campo da educação como objeto, entendendo-a como processo que enfrenta oposições tensionantes entre o experenciado historicamente, concepções coexistentes e a disputa na construção de outra realidade". Nessa concepção, as autoras pretendem, a partir disso, abordar os aspectos que favorecem ou obstaculizam a constituição de uma gestão democrática na escola. 
As autoras compreendem que para se efetiva uma gestão democrática da escola, é preciso, antes de tudo, constituir um espaço de encaminhamentos e decisões coletivas, que possibilite, também, a participação da sociedade, nesse contexto. Todavia, ressaltam que, a partir da Nova Gestão Pública (NGP), é transposto "os critérios do mercado econômico privado para o campo da educação, o neoliberalismo orienta uma série de medidas justificadas, contraditoriamente, como forma de atender às exigências dos movimentos sociais por maior participação" (COUTINHO; LAGARES, 2017, p. 841).

No trabalho intitulado Gestão democrática da educação para uma formação humana: conceitos e possibilidades, de autoria de Ferreira (2010), considera-se que não obstante a gestão democrática da educação configurar-se como um valor consagrado no Brasil, ainda não foi, em sua totalidade, compreendido e inserido à prática social da prática educativa nacional. Ferreira (2010, p. 167) salienta que, "É indubitável sua importância como um recurso de participação humana e de formação para a cidadania. É indubitável sua necessidade para a construção de uma sociedade mais justa e igualitária", pois é, em acréscimo, "indubitável sua importância como fonte de humanização".

O terceiro artigo possui o título de Concepções e práticas de gestão escolar democrática na educação básica no Brasil, suas autoras são Almeida e Silva (2017). A pesquisa objetiva compreender as concepções e práticas em que se efetua a gestão escolar democrática na educação básica brasileira. O diagnóstico das autoras sinaliza para uma alerta nessa temática, pois, para Almeida e Silva (2017, p. 121), “atualmente a gestão escolar, não tem permitido uma maior participação de todos os seus agentes na tomada de decisões". Com efeito, as autoras sugerem que "a escola precisa garantir a autonomia de todos os envolvidos no processo de ensino e aprendizagem, se organizando, para que finalmente possibilite o desenvolvimento de uma verdadeira ação democrática".

O artigo de Masson e Van Acker (2018, p. 88), intitulado: Educação escolar e gestão democrática do ensino: perspectivas, compreende que, no ambiente escolar, de modo gradual, “a expressão gestão educacional vem a substituir a de administração escolar, em meio a proposições acerca [de] novas formas de organização política e pedagógica das instituições que deveriam ter como fundamento a gestão democrática".

No tocante ao texto A gestão democrática e a materialização da Meta 6 do Plano Nacional de Educação: possibilidade de educação em tempo integral na região metropolitana do Estado do Rio de Janeiro (MOTA, 2018), a autora ressalta que a despeito da proposta de democratizar a gestão escolar seja progressiva no que concerne à participação igualitária entre 
gestores e professores, é necessário considerar o regime governamental hodierno, além das políticas da administração pública que as escolas devem, constantemente, interagir.

Amaral (2016) em seu texto Mérito, desempenho e participação nos planos municipais de educação: sentidos da gestão democrática, aborda que, numa gestão democrática da escola, todos os educadores podem se candidatar à direção da escola, não diferenciando, em nada, a formação. Com efeito, para ser diretor não é necessário ter exercido carreira docente, contudo, é crucial receber formação para tratar dos temas referidos ao ensino.

No texto Gestão escolar e democratização da escola: desafios e possibilidade de uma construção coletiva, os autores Bernado, Borde e Cerqueira (2018), objetivam analisar a gestão da escola sob a ótica democrática. Os autores compreendem que são diversos elementos que tornam factível a concepção democrática de gestão, um dele é a própria eleição de diretores, pois a base da gestão democrática corresponde à construção de um espaço público de direito, em que promover condições de liberdade, justiça, igualdade e diálogo em todas as vertentes, asseguram uma estrutura real para a uma educação de qualidade.

Amaral (2018), no trabalho intitulado Regulamentação da gestão democrática e a ação do Ministério Público: desdobramentos no estado do Rio de Janeiro, enfatiza a urgência da implantação, nos municípios, de gestão democrática nas escolas via processo democrática e participativo. Todavia, ressalta que essa temática ainda não é prioritária na pauta da agenda política de muitos municípios. Nessa acepção, é imperiosa a necessidade de regulamentar, em âmbito nacional - tendo em vista as confederações estaduais e municipais -, a gestão democrática, bem como os processos de eleições diretas para diretores de escolas. Apenas assim, para o autor, que será possível se opor aos interesses privados, tendo em vista a prioridade dos interesses públicos.

Para Nascimento e Cavalcanti (2017), no texto Gestão democrática na educação infantil, é dado atenção à aplicação da gestão democrática na educação infantil, considerando que é essencial - para que esse processo se consolide - a participação real de todos os sujeitos que constituem o processo educacional, além de não perder de vista todos os aparatos legais que vinculam-se a realidade escolar. O autor conclui que só é exequível superar os desafios da educação se houver efetiva participação da comunidade escolar, bem como dos órgãos públicos, visto que as políticas educativas possuem papel central nos encaminhamentos e rumos em que a escola deverá seguir.

Concernente o entrecruzamento da categoria temática Gestão democrática e o descritor escolar, o primeiro artigo, Gestão escolar democrática: desafios e perspectivas (BOSCHETTI; 
MOTA, 2016), discorre sobre os desafios da gestão democrática da escola. Os autores consideram que:

O processo de gestão escolar tem como função primordial a descentralização do desenvolvimento pedagógico e administrativo no sistema de ensino. $\mathrm{O}$ resultado desse gerenciamento é a crescente autonomia da escola diante do compromisso e envolvimento de todos os atores que participam dessa construção democrática. Portanto, o progresso de gestão evoca também vários indicadores a serem trabalhados, tais como a gestão participativa, relações interpessoais, desempenho e autoavaliação (BOSCHETTI; MOTA, 2016, p. 104).

O texto A gestão democrática das escolas: do autogoverno à ascensão de uma pósdemocracia gestionária? (LIMA, 2014, p. 1079-1080) assevera que

\begin{abstract}
A gestão democrática das escolas, enquanto autogovernos e, em boa parte, até mesmo enquanto conjunto de estruturas e de procedimentos democráticos, foi objeto de uma crítica sistemática por parte de setores políticas que concebem a democracia no governo das escolas como um exemplo dos desmandos progressistas na educação e das irresponsabilidades das lideranças colegiadas, que ainda é possível encontrar em certas organizações públicas. Organizações a que ainda não teriam chegado com suficiente intensidade os ventos modernizadores e racionalizadores da Nova Gestão Pública, apesar das marcas que essa ideologia gestionária tem deixado nas escolas, de forma indelével, segundo a pesquisa disponível.
\end{abstract}

Com efeito, o autor considera que nos marcos da concepção de gestão democrática diversos são os problemas, contudo, não é dado relevância à lógica da administração burocrática da escola. Nessa perspectiva, o terceiro artigo intitulado Gestão democrática da escola no Brasil: desafios à implantação de um novo modelo, de autoria de Vieira e Vidal (2015) compreende que a gestão democrática se configura como um eixo norteador da escola pública brasileira, consoante a Constituição Federal (BRASIL, 1988) e a LDB (BRASIL, 1996). Todavia, em função da ênfase dada às premiações adotadas por muitos Estados e municípios brasileiros, engendra-se, assim, um paradigma de conduta que se distancia do princípio da gestão escola democrática, pois, essa processualidade impõe uma cultura de gestão por resultados.

No que diz respeito à categoria temática Administração burocrática da escola, não obstante ter sido combinada com três descritores, apenas um deles gerou resultados que, por sua vez, apenas um artigo foi validado: Escolas de governo e seus objetivos institucionais em educação corporativa na administração pública (SANTOS; KANAANE, 2017). O texto busca destacar a relevância das formas de administrar o ambiente público, sejam em qual for a instituição, em especial a escola. O texto não se opõe a concepção de gestão democrática, 
contudo, faz diversos apontamentos à eficiência em administrar instituições nas quais o recurso público é canalizado. Nessa acepção, fortalece a dicotomia entre gestão democrática de um lado, e administração burocrática de outro.

A partir dos resultados, é evidente que o estado da arte acerca da temática centrada na lógica da gestão, é dado ênfase, em especial, para a construção e implantação de um modelo de gestão democrática nas escolas públicas de educação básica no Brasil. Não foi achado nenhum artigo que fazia oposição à ideia democrática de gestão. Com efeito, o sentido de administração escolar, pode sim, como foi ressaltado mais acima, empreender um caráter que envolva tanto a utilização racional dos recursos na escola, como voltar-se a lógica da gestão das atividades fins, em que o processo pedagógico seja a referência.

\section{Considerações finais}

O estado da arte acerca do tema gestão educacional e seus apontamentos para a dicotomia gestão democrática e administração burocrática da escola diagnosticou que o debate acadêmico, em sua totalidade, não se opõe à noção de democracia da forma de administrar uma escola, visto que o conceito de administração utilizado, no conteúdo, dos artigos validados em nossa análise consideram que administração configura-se como a utilização racional dos recursos para realizar seus fins, no tocante esses fins configuram-se como o processo pedagógico, isto é, o ensino e a aprendizagem.

Concernente à gestão democrática, essa forma de conceber o diretor enquanto educador e mediar os processos de gestão através da participação coletiva dos sujeitos que constituem a comunidade escolar, além das iniciativas para eleições diretas de diretores, ocupa a centralidade das análises apontadas no desenvolvimento do estado da arte.

No limite, é essencial irradiar o debate acerca das formas democráticas de gerir uma escola, disseminando o conceito de administração em que não seja circunscrito aos mecanismos burocráticos da instituição escolar, contudo, é preciso apontar para os aspectos que correspondem à realização dos fins, do processo pedagógico. Este conceito de administração escolar é essencial para constituir uma escola em que as decisões partam dos debates elencados pelos sujeitos da comunidade, dos educadores e dos gestores. 


\section{REFERÊNCIA}

ALMEIDA, W. F. T.; SILVA, J. B. Concepções e práticas de gestão escolar democrática na educação básica no Brasil. Revista Cadernos de Estudos e Pesquisa na Educação Básica, Recife, v. 3, n. 1, 2017. Disponível em:

https://www.google.com/url? sa=t\&rct=j\&q=\&esrc=s\&source=web\&cd=1\&cad=rja\&uact=8\& ved=2ahUKEwiHptutronhAhXHdN8KHXcsAgQQFjAAegQIChAC\&url=https\%3A\%2F\%2F periodicos.ufpe.br\%2Frevistas $\% 2$ Fcadernoscap $\% 2$ Farticle $\% 2 F d o w n l o a d \% 2 F 236104 \% 2 F 288$ 11\&usg=AOvVaw01Cjte79s4DYRnylfYtYsB. Acesso em: 15 mar. 2019.

AMARAL, D. P. Mérito, desempenho e participação nos planos municipais de educação: sentidos da gestão democrática. Revista on line de Política e Gestão Educacional, v. 20, n. 3, 2016. Disponível em: https://periodicos.fclar.unesp.br/rpge/article/view/9532. Acesso em: 15 mar. 2019.

AMARAL, D. P. A regulamentação da gestão democrática e a ação do ministério público: desdobramentos no estado do Rio de Janeiro. Revista On line de Política e Gestão Educacional, v. 22, n. esp. 1, 2018. Disponível em: https://periodicos.fclar.unesp.br/rpge/article/view/10781. Acesso em: 15 mar. 2019.

BERNADO, E. S.; BORDE, A. M.; CERQUEIRA, L. M. Gestão escolar e democratização da escola: desafios e possibilidades de uma construção coletiva. Revista online de Política e Gestão Educacional, v. 22, n.esp. 1, 2018. Disponível em:

https://periodicos.fclar.unesp.br/rpge/article/view/10782. Acesso em: 14 mar. 2019.

BOSCHETTI, V. R.; MOTA, A. B.; ABREU, D. L. F. Gestão escolar democrática: desafios e perspectivas. Rev. Gest. Aval. Educ., Santa Maria, v. 5, n. 10, 2016. Disponível em: https://www.google.com/url? sa=t\&rct=j\&q=\&esrc=s\&source=web\&cd=1\&cad=rja\&uact=8\& ved=2ahUKEwjSj5GCq4nhAhWWK7kGHakgDCMQFjAAegQIBxAC\&url=https\%3A\%2F $\% 2$ Fperiodicos.ufsm.br\%2Fregae \%2Farticle\%2Fdownload\%2F22257\%2Fpdf\&usg=AOvVa w1GcGwfgOfCAOcmPKYOhzQh. Acesso em: 17 mar. 2019.

BRASIL. Planalto. Constituição Federal. Brasília, 1988.

BRASIL, Lei 9.394, de 20 de dezembro de 1996. Estabelece as Diretrizes e Bases da Educação Nacional. Disponível em: http://www.planalto.gov.br/ccivil_03/LEIS/L9394.htm. Acesso em: 21 mar. de 2019.

COUTINHO, L. P.; LAGARES, R. Dilemas da gestão democrática da educação frente ao contexto da nova gestão pública. Revista brasileira de política e Administração da Educação, v. 33, n. 3, 2017. Disponível em: https://seer.ufrgs.br/rbpae/article/view/76080. Acesso em: 16 mar. 2019.

FERREIRA, N. S. C. Gestão democrática da educação para uma formação humana: conceitos e possibilidades. Em aberto, v. 17, n. 72, 2000. Disponível em:

http://rbep.inep.gov.br/index.php/emaberto/article/view/2130. Acesso em: 15 mar. 2019.

GAMBOA, S. S. Epistemologia da pesquisa em educação. Campinas: Práxis, 1998. 
LIMA, L. C. A Gestão Democrática das Escolas: do autogoverno à ascensão de uma pósdemocracia gestionária? Educ. Soc. [online], vol.35, n.129, 2014. Disponível em: http://dx.doi.org/10.1590/ES0101-73302014142170. Acesso em 16 mar. 2019.

MASSON, M. A. C.; VAN ACKER, M. T. V. Educação escolar e gestão democrática do ensino: perspectivas. Revista on line de Política e Gestão Educacional, v. 22, n.esp. 1, 2018. Disponível em: https://periodicos.fclar.unesp.br/rpge/article/view/10785. Acesso em: 15 mar. 2019.

MOTA, P. F. A gestão democrática e a materialização da Meta 6 do Plano Nacional de Educação: possibilidade de educação em tempo integral na região metropolitana do Estado do Rio de Janeiro. Revista on line de Política e Gestão Educacional, v. 22, n. 1, 2018. Disponível em: https://periodicos.fclar.unesp.br/rpge/article/view/10703. Acesso em: 15 mar. 2019.

NASCIMENTO, L. F.; CAVALCANTI, M. M. D. Gestão democrática na educação infantil. Revista on line de Política e Gestão Educacional, v. 22, n. 1, 2017. Disponível em: https://periodicos.fclar.unesp.br/rpge/article/view/9991. Acesso em: 15 mar. 2019.

NETTO, José Paulo. Introdução do estudo do método em Marx. São Paulo: Expressão Popular, 2011.

SANTOS, D. P. A.; KANAANE, R. Escolas de governo e seus objetivos institucionais em educação corporativa na administração pública. Pós-graduação e pesquisa do Centro Paula Souza, n. 1, 2017. Disponível em: http://www.portal.cps.sp.gov.br/pos-graduacao/workshopde-pos-graduacao-e-pesquisa/012-workshop-

2017/workshop/artigos/Educacao/Educacao_Corporativa/Escolas-de-Governo-e-seusObjetivos-Institucionais.pdf. Acesso em: 17 mar. 2019.

VIEIRA, S. L.; VIDAL, E. M. Gestão democrática da escola no Brasil: desafios à implementação de um novo modelo. Revista Iberoamericana de Educación, n. 67, 2015. Disponível em:

https://www.google.com/url?sa=t\&rct=j\&q=\&esrc=s\&source=web\&cd=1\&cad=rja\&uact=8\& ved=2ahUKEwjvu-

2crInhAhW_LLkGHeUsBjkQFjAAegQIChAC\&url=https\%3A\%2F\%2Frieoei.org\%2Fhistori co\%2Fdocumentos\%2Frie67a01.pdf\&usg=AOvVaw3DiqppKnOrTq7riAoI_G1d. Acesso em: 16 mar. 2019.

\section{Como referenciar este artigo}

PAULA, Alisson Slider do Nascimento; COSTA, Frederico Jorge Ferreira; LIMA, Kátia Regina Rodrigues. A contradição gestão democrática $\mathrm{x}$ administração burocrática da escola: apontamentos para o debate. Revista on line de Política e Gestão Educacional, Araraquara, v. 23, n. 2, p. 388-400, maio/ago., 2019. E-ISSN:1519-9029. 10.22633/rpge.v23i2.12443

Submetido em: 17/03/2019

Revisões requeridas: 04/04/2019

Aprovado em: 28/04/2019

Publicado em: 15/05/2019 